NASA Technical Memorandum 105152

AIAA-90-2552

\title{
Multimegawatt Electric Propulsion System Design Considerations
}

J.H. Gilland and R.M. Myers

Sverdrup Technology, Inc.

Lewis Research Center Group

Brook Park, Ohio

and

M.J. Patterson

Lewis Research Center

Cleveland, Ohio

Prepared for the

21st International Electric Propulsion Conference

sponsored by the American Institute of Aeronautics and Astronautics

Orlando, Florida, July 18-20, 1990

\section{NASn}




\title{
MULTIMEGAWATT ELECTRIC PROPULSION SYSTEM DESIGN CONSIDERATIONS
}

\author{
J. H. Gilland*, R. M. Myers**, and \\ Sverdrup Technology, Inc. \\ Lewis Research Center Group \\ Brookpark, Ohio 44142 \\ M. J. Patterson ${ }^{+}$ \\ National Aeronautics and Space Administration \\ Lewis Research Center \\ Cleveland, Ohio 44135
}

Piloted Mars mission requirements of relatively short trip times and low initial mass in Earth orbit as identified by the NASA Space Exploration Initiative, indicate the need for multimegawatt electric propulsion systems. The design considerations and results for two thruster types, the argon ion and hydrogen magnetoplasmadynamic thrusters, are addressed in terms of configuration, performance, and mass projections. Preliminary estimates of Power Management and Distribution for these systems are given. Some assessment of these systems' performance in a reference Space Exploration Initiative piloted mission are discussed. Research and development requirements of these systems are also described.

\section{Introduction}

In the past 5 years, human exploration of the Moon and Mars has arisen as a worthy goal for America and NASA to pursue. Such an undertaking requires a great deal of planning, as well as the judicious use of advanced technology to achieve the goal as efficiently as possible. In the area of propulsion, a safe, propellant efficient, means of space travel is a necessary component in the missions. Systems currently under consideration by the NASA Office of Aeronautics, Exploration and Technology (OAET) are cryogenic and storable chemical propulsion, nuclear thermal propulsion, and nuclear and solar electric propulsion (NEP, SEP). Of these systems, the electric propulsion systems are unique in that they consist of two components which operate in tandem: the space power supply and the electric propulsion thrusters. In order to permit a reasonable assessment of entire electric propulsion (EP) systems, the design of two specific forms of electric thrusters have been analyzed by the Space Propulsion Technology Division (SPTD) and Advanced Space Analysis Office (ASAO) of NASA Lewis Research Center.

* Research Engineer, Sverdrup Technology, Inc. Member AIAA.

** Plasma Propulsion Engineer, Sverdrup Technology, Inc. Member AIAA.

+ Aerospace Engineer, NASA Lewis Research Center. Member AIAA.
By thrusting at specific impulses of 4,000 to $10,000 \mathrm{~s}$ over most of the mission, electric propulsion vehicles are capable of reaching their destination with $50 \%$ less initial mass than a cryogenic hydrogen/oxygen chemical aerobrake mission1.2. Lunar and Mars missions using electric propulsion require a significant increase from the $\mathrm{kWe}$ power levels envisioned for near term missions in Earth orbit or on interplanetary probes. Power levels from 1 to tens of megawatts (MWe) are required in order to accomplish an oppositionclass Mars mission in trip times comparable to chemical missions ${ }^{3}$. Both solar and nuclear space power supplies may be capable of providing the needed power; these systems share the common need of thruster parameters to allow effective propulsion system and vehicle design. Preliminary thruster performance, design and development issues have been determined for two of the more promising types of electric propulsion: the argon ion engine and the magnetoplasmadynamic (MPD) thruster.

\section{High Power Electric Propulsion}

Megawatt level electric propulsion has been periodically considered for Mars missions for more than 3 decades 3-11. The present states of both space power and electric propulsion technologies do not allow mission designers to utilize available systemperformance and masses; instead, the EP vehicle must be assessed using projections of systems data based upon low power systems currently in use and experimental results. 
The argon ion engine and the MPD thruster have different requirements in terms of extrapolating the technology and design. Low power ion engine technology is well established, having been under development for over 30 years. Currently, electron bombardment, two-grid Xenon ion thrusters are available as flight systems 12 at $1.4 \mathrm{kWe}$, and higher power noble gas thrusters of 30 and $50 \mathrm{~cm}$ beam diameters are under development at NASA Lewis Research Center 13,14 The present incarnations of these devices are based on extensive research over the past decades on mercury ion thrusters, which are now supplanted by noble gas propellants using the same technology. In the past, mercury thrusters with $1.5 \mathrm{~m}$ diameter grids attained power levels of $100-250 \mathrm{kWe}$ in the laboratory 15 . The physics of these devices is fairly well established at the lower power levels, and reasonable performance projections can be made based on the lower power systems. The technology challenge lies in the design and testing of ion thrusters that can maintain this performance over lifetimes of $\sim 10,000$ hours at megawatt power levels. The issues inherent in these designs will be discussed in detail accompanying the ion thruster design.

Conversely, laboratory MPD thrusters have been found to be particularly effective at the $.1-10 \mathrm{MWe}$ power levels, but the lifetimes and performance desired for use in a Mars or Lunar vehicle have not yet been demonstrated. Megawatt level MPD thrusters, both selffield and applied field, have been operated in a pulsed mode for milliseconds at a time, and in some cases have attained thousands of pulses. $16,17,18$ Recently, steady state devices have been operated at levels from 10 - 700 $\mathrm{kWe}$, and the physics of the devices under both pulsed and steady conditions is being compared 19,20 . To summarize, ion thruster performance physics have been somewhat defined at low power levels, while MPD thruster performance physics are still being assessed under the conditions required for effective plasma acceleration.

While electric propulsion promises reduction in propellant mass for demanding missions, studies of its implementation at megawatt power levels require thoughtful extrapolation of existing experimental data. The current understanding of electric propulsion is sufficient to address to some level the engineering aspects of these devices without resorting to technologies beyond reasonable projections of current technologies. Electric propulsion system designs in the past are often the result of either the conservative application of available thruster technologies 3,10 , or the optimistic use of technologies that require projections of electric propulsion design beyond the expectation of current research $5,7,9$. For example, because the $30 \mathrm{~cm}$ thruster is the most advanced thruster currently available, some electric propulsion designs have resorted to operating tens to hundreds of small 30 or $50 \mathrm{~cm}$ diameter thrusters, at $10-30 \mathrm{kWe}$ each, to absorb megawatts of power $3,10,11$. The sheer complexity of using a multitude of thrusters with their attendant power processing and distribution systems raises significant feasibility issues that cannot be taken lightly.

Similarly, MPD thruster designs have often utilized a single compact MPD thruster to absorb the entire $1-10$ MWe power load, relying on the MPD thruster's well known capacity for high plasma power densities to process the power into thrust 7,8,9. While quasi-steady state MPD thrusters have a laboratory demonstrated ability to process $\mathrm{MW}$ of power in a cylindrical plasma volume $10 \mathrm{~cm}$ long and $10 \mathrm{~cm}$ diameter, or even smaller ${ }^{21}$, the issues of heat rejection and electrode erosion over an extended period of steady state operation prove to be more critical than the anticipated plasma properties in developing an engineering design. To address the heat rejection issue, some designers have resorted to a "unique," singleelement annular heat pipe surrounding the thruster anode as a radiator; however, some designs using this concept resort to utilizing heat fluxes to the radiator up to 1200 $W / \mathrm{cm}^{2}$ - sigitificantly higher than any value measured in present small scale heat pipes.9,22 It is of interest to determine the potential benefits of a more realistic design which could be developed with technology projected to be available in the near future; the benefits of electric propulsion may be substantial even with a less optimistic design.

\section{Electric Propulsion Thruster Designs}

\section{MPD Thruster}

Thruster Performance: Megawatt MPD thruster design relies on performance data for steady state and quasi-steady applied-and self-field thrusters operated at powers from $10-10,000 \mathrm{kWe}$, using a variety of propellants and electrode designs. The highest specific impulses and efficiencies measured to date have been obtained using hydrogen and lithium propellants Spacecraft contamination issues may preclude the use of condensable metal propellants such as lithium or mercury; therefore, hydrogen is the propellant of choice. Analysis of thruster performance with a variety of propellants has led to several theories of MPD performance modelling; some aspects of these models 23 have been used in conjunction with experimental dat 24 
to generate thruster efficiency as a function of input power and specific impulse. These results have been used to project thruster performance for electric propulsion mission analysis as well as to determine desired operating conditions for the current thruster design.

Scaled tests have indicated substantial performance benefits from using an applied magnetic field $18,25,26$ While it is not currently possible to specify the required field shape or strength, existing data suggest that thruster efficiency and specific impulse increase monotonically with magnetic field strength. Testing showed that axial field strengths in excess of 0.3 Tesla (T) may be required to achieve the desired efficiency and specific impulse. In addition, Tahara and Sasoh report that the shape of the field may be at least as important as its strength in determining thruster performance. 18,27 For this study, it was assumed that a simple solenoidal field would be sufficient, and the design parameters have been chosen such that a change in field configuration would not dramatically impact the thruster specific mass.

Figure 1 shows projected MPD thruster performance for specific impulse values up to 6000 seconds using hydrogen propellant. These calculations represent a projection of steady state megawatt level applied field MPD thruster performance based on experimental data and the current thruster design ${ }^{24}$. Thruster efficiency can be expressed in a parametric fashion using the functional form $n=b^{*} c /(c+d)$, where $c$ is the exhaust velocity ( $c$ $=$ specific impulse ${ }^{*} \mathrm{~g}$ ) and $\mathrm{b}$ and $\mathrm{d}$ are derived from experimental data. In Figure 1 , the parameters $b=.858$ (dimensionless) and $d=2.59 \times 10^{4}(\mathrm{~m} / \mathrm{s})$ apply. Efficiency is seen to increase with specific impulse and with power level, with peak values on the order of 50 $60 \%$ at the upper limit of specific impulse. At the present time, the limit of $6000 \mathrm{~s}$ is due only to a lack of data at higher levels of specific impulse, which tend to require higher current and power levels. Theory presently indicates no physical limit in attaining higher specific impulses with hydrogen MPD thrusters. Further research into thruster behavior and performance may result in quantitative changes to these projected data; however, it is expected that qualitative MPD thruster behavior will remain as shown in the figure.

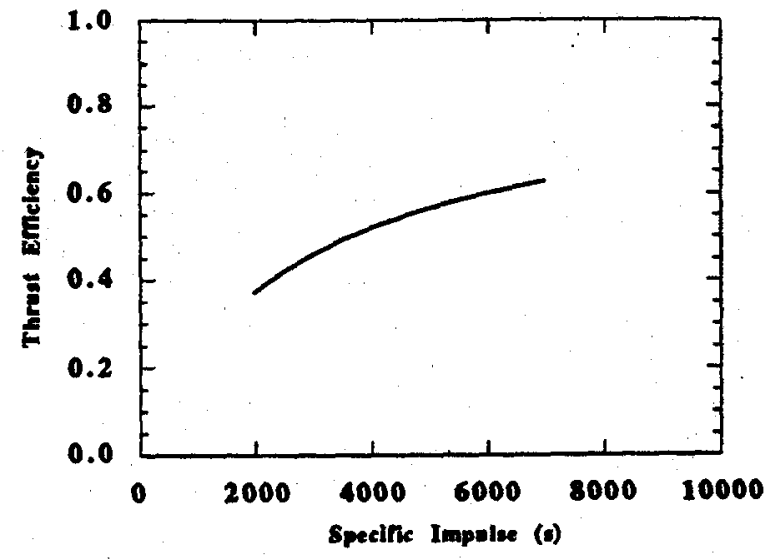

Figure 1. Projected Hydrogen MPD Thruster Performance at $2.5 \mathrm{MWe}$.

MPD Thruster Design: Thruster performance data have been incorporated with mission design requirements, including heat rejection needs. System simplicity was used as a primary goal in thruster design. The final design for a $2.5 \mathrm{MWe}$ MPD thruster is shown in Figure 2. It consists of a flared molybdenum anode and a low work function material impregnated, porous tungsten cathode. The applied. magnetic field coil is made from aluminum and is cooled to $21 \mathrm{~K}$ using the liquid hydrogen propellant supplied to the thruster. This cooling reduces the power dissipation within the magnet to approximately $0.1 \mathrm{~kW}$ by lowering the material resistivity. After cooling the magnet, the hydrogen enters the thrust chamber through the boron nitride backplate at the rear. The magnet is also separated from the hot anode surface by a set of 20 tantalum radiation heat shields. The anode itself is cooled by a set of 50 one $\mathrm{cm}$ radius lithium heat pipes operating at a temperature of $1400 \mathrm{~K}$. The fibers of the one meter diameter pyrolitic graphite radiator are arranged azimuthally to distribute heat evenly about the entire radiator surface. The design operating point for this thruster is $10,000 \mathrm{~A}, 250 \mathrm{~V}$ with a hydrogen mass flow rate of $2.5 \mathrm{~g} / \mathrm{s}$. The magnet coil is designed for $2500 \mathrm{~A}$ with a voltage drop of $0.04 \mathrm{~V}$, providing a field strength of $0.4 \mathrm{~T}$ at the cathode tip. The specific mass of the MPD thruster shown is estimated to be 0.17 $\mathrm{kg} / \mathrm{kWe}$, and scaling to higher powers is governed by the anode heat transfer and the cathode current density limitation. 


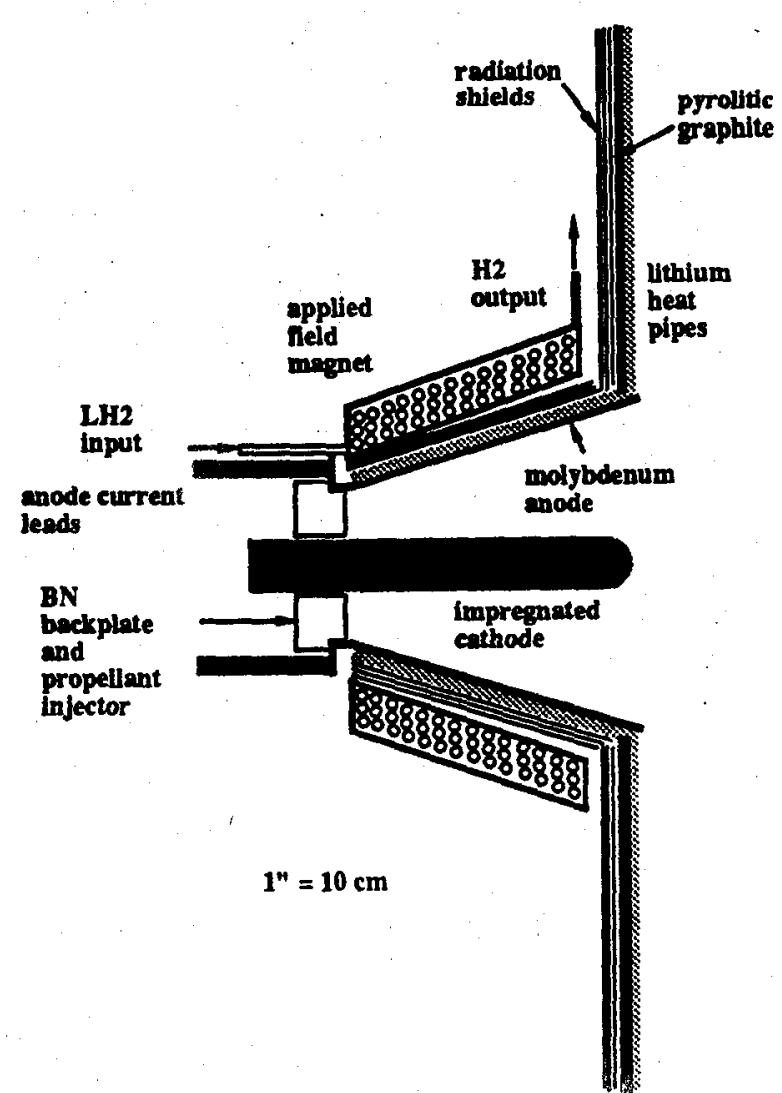

Figure 2. 2.5 MWe MPD Thisuser Design Schematic.

The required overall thruster terminal characteristics of current, voltage, and mass flow were established by considering the required thruster performance and total available power. To prevent major electrode losses, the combined voltage drops at the anode and cathode must be a small fraction of the total terminal voltage. Recent studies have shown the combined fall voltages to range from 20 to 30 volts 25,28 , so the total thruster voltage drop must be between 200 and 300 volts to keep the electrode losses below $10 \%$. For a 2 to $5 \mathrm{MW}$ system this yields an available current range from 7,000 to $25,000 \mathrm{~A}$. This range can be narrowed further through analysis of anode and cathode heat and conduction limits.

Cathode Design: The cathode lifetime requirement, geometry, and material fix the maximum discharge current capability of the thruster. Only solid cathode geometries are considered; the uncertainties associated with hollow cathode operation in MPD thrusters precludes their inclusion in this study. The longest demonstrated cathode lifetimes have been obtained using a metal oxide impregnated tungsten cathode. Lifetimes over 6000 hours have been demonstrated in tests with current densities below $15 \mathrm{~A} / \mathrm{cm}^{2} .29$ The surface temperature for these experiments was below $1473 \mathrm{~K}$, which is substantially lower than the over $3000 \mathrm{~K}$ temperatures observed with $2 \%$ thoriated tungsten (ThW) cathodes presently used in laboratory MPD thrusters ${ }^{30}$. This temperature reduction has the added benefit of reducing the thermal stresses on the cathode supports and the insulator at the rear of the chamber. Given the maximum surface current density, the cathode size was established using the total current to the thruster. A current level of $10,000 \mathrm{~A}$ was selected as a reference point. This criterion requires a cathode $5 \mathrm{~cm}$ in diameter and $23 \mathrm{~cm}$ long. The surface must be grooved or textured to provide a factor of two increase in surface area over a smooth cylinder. Such texturing processes are currently available and in use in thruster research. It will also be necessary to transit to a copper conductor as close to the thruster as possible to minimize the resistive dissipation in the cathode. The thermal problems this requirement entails may be alleviated by passing the hydrogen propellant through the cathode and anode conductors after it has cooled the applied field magnet.

Anode Design: The anode geometry is fixed by the combined performance and heat rejection requirements. Electromagnetic thrust is proportional to the logarithm of the anode to cathode radius ratio $\left(R_{a} / R_{c}\right)^{31}$. Pulsed quasi-steady tests with thrusters having $\left(R_{a} / R_{c}\right)=5$ have indicated the capability to achieve the desired specific impulse range.32,33 In addition, other tests in Japan have shown that a flared anode performs significantly better than a straight cylindrical shape. 18 Multimegawat quasi-steady testing has shown that approximately $10 \%$ of the thruster input power is deposited into the anode, indicating a heat rejection requirement for the present thruster design of approximately $200 \mathrm{~kW}$ at the design operating point. Based on the calculated conduction capability of W-Li heat pipes, $501 \mathrm{~cm}$ radius pipes were required. Accommodation of this heat pipe array at the anode exit plane, in combination with the performance requirements, led to the choice of a flared anode, with a $15 \mathrm{~cm}$ upstream diameter and $30 \mathrm{~cm}$ downstream diameter. The anode length is $23 \mathrm{~cm}$ to match the cathode length, as this design has been found to allow a greater range of operation in quasi-steady laboratory test ${ }^{34}$. The use of lithium heat pipes to cool the anode allows the use of molybdenum instead of tungsten, with an associated weight savings. The anode wall thickness is $0.5 \mathrm{~cm}$ to allow the required heat conduction to the heat pipes, which are bonded to the anode outer surface.

Heat Rejection: Cylindrical lithium heat pipes were selected due to their high operating temperature, 
heat transfer capabilities and simplicity 22 . The radial heat flux from the anode into the heat pipes is estimated to be $130 \mathrm{~W} / \mathrm{cm}^{2}$, leading to selection of SGS-tantalum for the wick material. This wick has been tested at radial heat fluxes up to $250 \mathrm{~W} / \mathrm{cm}^{2}$, and this is not thought to be a limiting value. With an operating temperature of $1400 \mathrm{~K}$ the specified heat pipe array can carry over $400 \mathrm{~kW}$ of waste heat away from the anode and reduce the required radiator surface area. The primary heat pipe design concern for this application is the sonic limit to axial heat conduction. For the specified design of $1 \mathrm{~cm}$ radius, these heat pipes were found to be more than an order of magnitude below this limit. Life tests of an titanium-zirconium-molybdenum (TZM) wall, lithium working fluid pipe indicate lifetimes in excess of 9000 hours 22 . Assuming a surface coating with an emissivity of 0.9 , the required radiator diameter is 0.7 $\mathrm{m}$, including the central void occupied by the thruster. The diameter has been increased to $1 \mathrm{~m}$ to provide a margin for expansion or increased power level. The rear of the radiator is coated with a low emissivity material to reduce heat transfer to the radiation shields separating it from the magnet and spacecraft.

Magnet Design: A principal consideration in designing the applied field magnet is that the power dissipated within the coils must be a negligible fraction of the total thruster power. Previous investigators have approached this problem by designing magnets of superconducting coils 35 . However, the attendant complexity of the liquid helium cooling system impairs the credibility of these concepts. The advent of hightemperature superconductors may solve these problems if current research is successful in surpassing the current density limitations of the present materials. In this study the magnet power issue is addressed by noting that the resistivity of aluminum at liquid hydrogen temperatures is low enough to reduce the dissipated magnet power to $0.1 \mathrm{kWe}$ at $2500 \mathrm{~A} .{ }^{36}$ The magnet coil consists of 50 turns of $1 \mathrm{~cm}$ diameter solid aluminum cable. The inner diameter of the coil is $2 \mathrm{~cm}$ greater than that of the outer anode heat pipe surface, and the coil contours follow the anode flare. Total coil length is $15 \mathrm{~cm}$ and there is a $2 \mathrm{~cm}$ gap between the rear of the anode radiator and the coil.

To prevent thermal runaway in the coil, the liquid hydrogen propellant must absorb all the heat generated within the coils and any heat radiated to the magnet from the anode or radiator surfaces. The radiative heat transfer is minimized using tantalum heat shields in the $2 \mathrm{~cm}$ gap between the heat pipes and coil surface. At heat pipe/radiator temperatures of $1400 \mathrm{~K}$ the total heat radiated to the magnet is less than $10 \mathrm{~kW}$, and 20 reflective heat shields can reduce this to less than 0.2 $\mathrm{kW}$. This heat and the resistive heat are then removed through the heating and partial vaporization of the liquid hydrogen propellant. Using the heat of vaporization (441 J/g at $101.3 \mathrm{kPa}$ ) and assuming the hydrogen enters the magnet as a saturated liquid, less than $1.5 \mathrm{~g} / \mathrm{s}$ of liquid hydrogen will evaporate at the maximum estimated operating power level of thruster and magnet. The use of slush hydrogen, as proposed for use in chemical transfer vehicles, would increase the cooling capability somewhat, but is not a required technology in this regard. While some detailed design efforts will be needed to prevent vapor-lock from causing local overheating, this is probably much less of a problem than designing closed loop liquid helium refrigeration systems for superconducting systems. The propellant should leave the magnet at $21 \mathrm{~K}$ and can then be used to cool other components. For mass flow rates greater than $1.5 \mathrm{~g} / \mathrm{s}$, the additional cooling could be used for the backplate and cathode base.

Overall Thruster Parameters: Thruster system component masses are shown in Table 1 . The heat rejection system is the predominant mass, with the cathode a distant second. Using molybdenum instead of tungsten reduced the anode mass by almost $50 \%$. the total thruster system mass is $337 \mathrm{~kg}$, yielding a specific mass of $0.17 \mathrm{~kg} / \mathrm{kWe}$ for the $2.5 \mathrm{MWe}$ operating point. It should be moted that the design parameters chosen were substantially higher than the minimum requirements for this operating point. The design described here is projected to be capable of operation over a range of powers from 1 - $3 \mathrm{MWe}$, at specific impulse levels from 4000 to 6000 seconds.

There are several operational issues which must be considered for this design. First, the magnet must be precooled with liquid hydrogen to $21 \mathrm{~K}$ before any current is supplied to it. This will necessarily waste some propellant. This implies some slow start-up procedure during which the thruster is brought up to its operating point. The capability to control the thruster and magnet current must therefore be provided, and the power supply must be able to sustain the thruster discharge over the full start up and operating range.

The principle assumptions in this study involve the performance characteristics of multimegawatt, steady-state MPD thrusters. It is clear that these data must be verified before detailed design is possible. While the results may impact the specific electrode and applied field configurations, the principal results of this study will probably not change: 1.) There are no mass or power penalties associated with 
using applied field magnets when cryogenic hydrogen is used as the propellant. Integration of the propellant supply and magnet cooling was sufficient to eliminate these issues without invoking superconductivity. 2.) A passive heat rejection system is more than adequate for the thruster power levels currently contemplated for missions to the Moon and Mars. The technologies utilized in this design have all been demonstrated in subscale tests. 3.) The total size of a MPD thruster system, including heat rejection, is approximately $1 \mathrm{~m}^{2}$ for a $2.5 \mathrm{MWe}$ thruster. 4.) The specific mass of the MPD thruster system is approximately $0.17 \mathrm{~kg} / \mathrm{kWe}$.

The limiting factors for higher power operation are the anode surface area, which controls the radial heat flux into the heat pipes, and the cathode surface area, which must be scaled according to current density limitations. In relation to the anode sizing, the limits of passive heat rejection systems such as lithium heat pipes must be established. At heat fluxes beyond those limits, an electromagnetic pumped-loop active cooling system could be used. For the cathode design, it is possible that using a different cathode material could substantially increase the cathode's current density capability and permit operation at higher currents without a change in cathode geometry. Variations in electrode size and mass have been seen to have, only a slight effect on overall system mass, and the sivenific mass of the system is not expected to thange substantially from the value calculate here. The coupling between thruster geometry and thisuster performance must be established before these scaling issues can be quantitatively addressed.

Table 1: Estimated MPD thruster system component masses

\begin{tabular}{|c|c|}
\hline Component & Mass (kg) \\
\hline 50 Heat Pipes & 113 \\
\hline Graphite Radiator & 92 \\
\hline \multicolumn{2}{|l|}{ Heat Shields/ } \\
\hline Supports & 30 \\
\hline Cathode & 40 \\
\hline Anode & 17 \\
\hline Backplate/Injector & 1 \\
\hline \multicolumn{2}{|l|}{ Magnet Coil/ } \\
\hline Enclosure & 13 \\
\hline Subtotal & 306 \\
\hline $10 \%$ Contingency & $\frac{31}{237}$ \\
\hline Total & 337 \\
\hline
\end{tabular}

\section{lon Thruster}

Thruster Performance: For the application of ion engines to a multimegawatt propulsion system for a
Lunar or Mars exploration initiative, there are a number of mission requirements which drive the design and operating parameters of the engines. These missions require a high engine thrust/power ratio to minimize trip times, a high beam power per unit area to reduce the number of thrusters required, a suitably high specific impulse to minimize vehicle propellant mass, and a propellant consistent with the above specific impulse as well as with vehicle contamination issues. Performance of these engines has been examined in terms of operating and design constraints identified through experiment and analysis, and these data have been extended to the megawatt power levels for this study. Ion thruster performance is governed by ionization energy requirements of the propellant, plasma generation efficiency, and allowable beam current densities for argon propellant. Ion thruster efficiency variation with specific impulse can typically be characterized by a functional relation of the form $n=$ $b^{*} c^{2} /\left(c^{2}+d^{2}\right)$ where $c$ is the exhaust velocity (c = $\mathrm{g}^{*}$ specific impulse), and $b$ and $d$ are parameters determined primarily by the propellant choice. Thruster efficiency as a function of specific impulse has been estimated for argon propellant based on these constraints, and is shown in Figure 3. In the case of argon, the two parameters $b$ and $d$ are .835 (dimensionless) and $22500 \mathrm{~m} / \mathrm{s}$.

Design constraints are those thruster design parameters which define the maximum beam power and thrust obtainable for each engine. These constraints are 1.) ion optics span-to-gap ratio, 2.) the intragrid electric field strength, 3.) the discharge power per unit beam area, and 4.) the ion optics electrode lifetime for both screen and accelerator grids ${ }^{37}$. The operating constraints define the range of available specific impulse for a given propellant and total accelerating voltage. These constraints are a lower specific impulse limit defined by the minimum net-to-total accelerating voltage ratio (the "R-ratio") 13 , below which ion defocussing and impingement of the ions onto the grids occur; and an upper limit to the R-ratio, beyond which value neutralizing electrons backstream into the screen electrode.

The effects of design constraints on thruster beam pswer and thrust level are shown in Figures 4 and 5. Beam power is defined as the power imparted to the ion flow before incurring losses due to divergence, neutrals, and doubly ionized species. Electric-to-beam power conversion efficiency is quite high, greater than $90 \%$; other losses reduce the total electric-to-thrust efficiency to the values shown in Figure 3. 


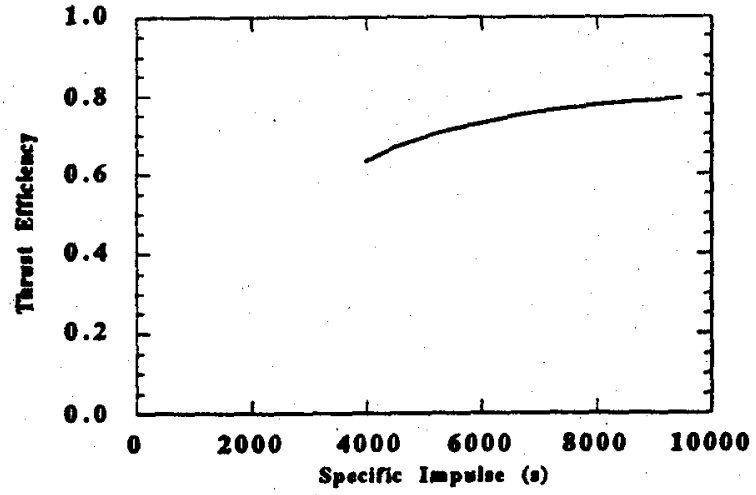

Figure 3. Projected Argon Ion Thruster Performance.

This behavior is based on an assumed total accelerating voltage of $2000 \mathrm{~V}$ and beam current density of $153 \mathrm{~A} / \mathrm{m}^{2}$. The total accelerating voltage is the sum of the absolute values of screen and acceleration grid voltages. The ratio of the screen voltage to the total voltage, $R$, determines the specific impulse of the device. The screen grid voltage for the design point of $7800 \mathrm{~s}$ specific impulse is $1680 \mathrm{~V}$, corresponding to a $R$ value of 0.84 . These parameters have been derived from experimental $30 \mathrm{~cm}$ xenon ion thruster results, and will be discussed further in the thruster design description. Chief considerations in this scaling estimate are space charge limitations on power per unit beam area, and electrode lifetime limits.

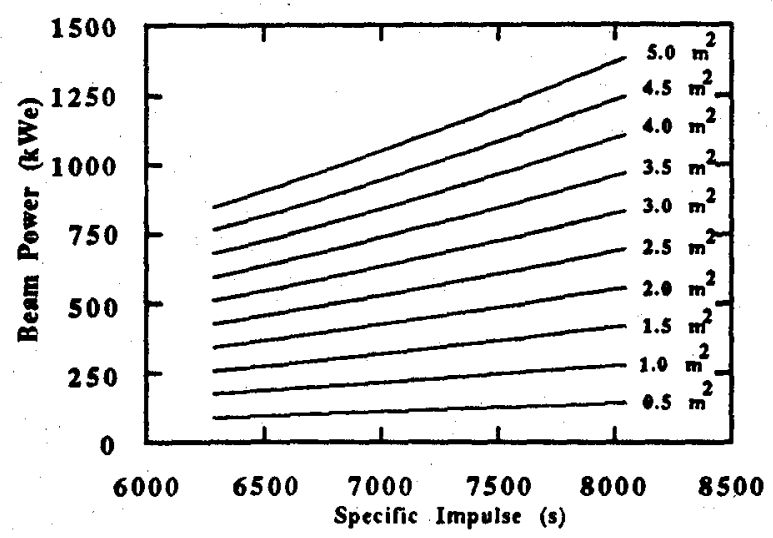

Figure 4. Scaling of Argon Ion Thruster Beam Power with Specific Impulse, Beam Area.

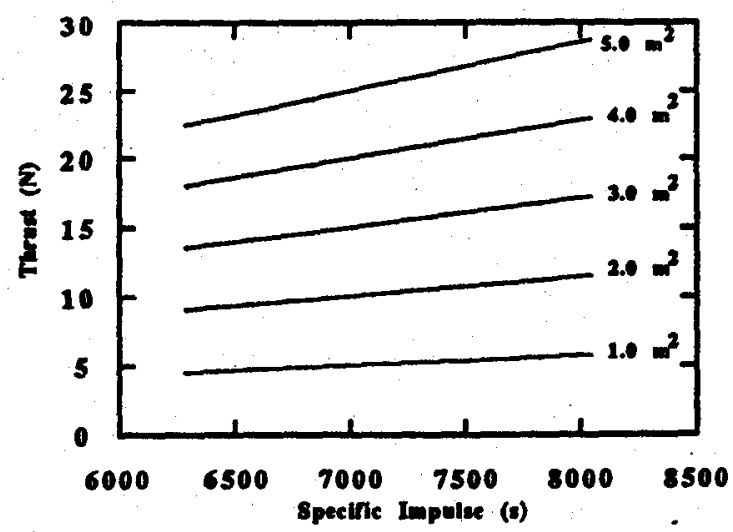

Figure 5. Scaling of Argon Ion Thruster Thrust with Specific Impulse and Beam Area.

Ion Thruster Design: A point design for a MWe-level argon ion thruster addresses the design and performance of the three major subsystems: ion. production, ion extraction, and beam neutralization. Assumptions and development requirements for each subsystem have also been identified. The available range of specific impulse, thrust, efficiency, and hence beam power are all included in these designs. An illustrative configuration for this $\mathrm{MWe}$ argon ion thruster study is given in Figure 6; specific components of this design are discussed in greater detail in the following sections.

Ion Production Subsystem: A variety of methods can be used to create the ions, the most conventional of which is by electron bombardment of the propellant from a hollow cathode in a DC discharge. The megawatt level ion production system is scaled from current conventional low power inert gas thrusters ${ }^{38}$. The system consists of a low work function material impregnated discharge hollow cathode and corresponding anode system located on the interior of the discharge chamber. The principal differences in this megawatt subsystem design relative to today's 5 . $10 \mathrm{kWe}$ class laboratory thrusters are a substantially larger chamber volume to accommodate the larger areas required for high power levels, and the multiple (10) hollow cathodes operating in a current-sharing mode to insure a uniform plasma density and reduce the sizing requirements of the cathodes. The discharge chamber itself is assumed to be steel and is sized to accommodate a $1 \mathrm{~m} \mathrm{X} 5 \mathrm{~m}$ discharge and beam area. Structural elements in the thruster chamber are titanium. 


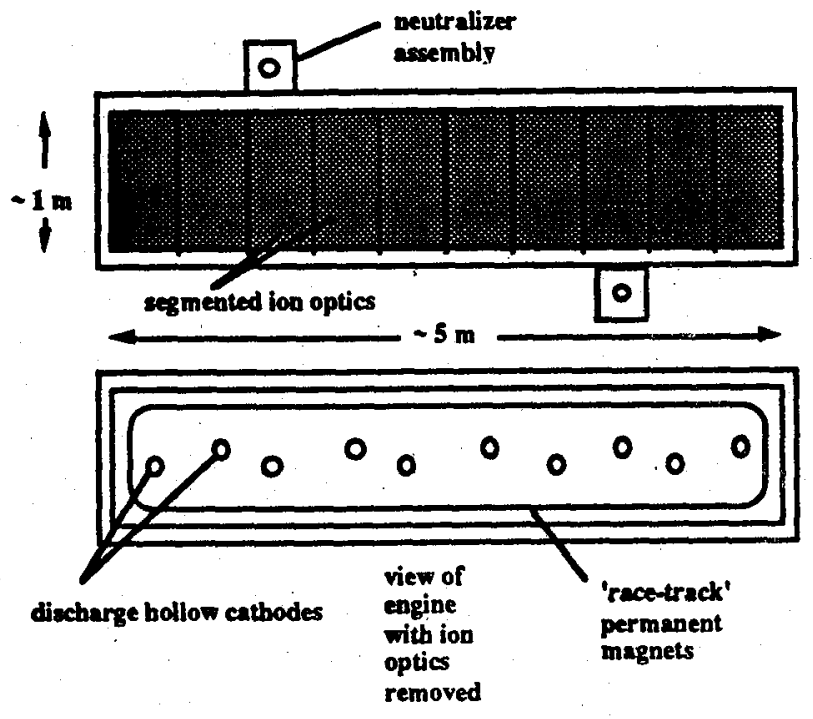

Figure 6. Megawatt Argon Ion Engine Schematic.

For ion engines of the size required for MWe operation, the hollow cathodes utilize molybdenum and thoriated tungsten structural components together with low work function impregnant inserts to increase ion production efficiency and life. Ten cylindrical hollow cathodes are distributed over the rear wall of the discharge chamber to operate in a current sharing mode at a nominal $358 \mathrm{~A}$ emission current per cathode. The cathodes form a plasma with the electron current confined between the cathode discharges and a stainless steel anode along the side walls of the discharge chamber. For the reference $5 \mathrm{~m}^{2}$ beam area, the anode dimensions are $1 \mathrm{~m}$ width $X 5 \mathrm{~m}$ length $X 0.5 \mathrm{~m}$ depth. "Race track" arrays of permanent magnets along the side and rear walls form a ring-cusp magnetic circuit similar to that utilized in existing low power thrusters. The magnets are arranged in rings of alternating polarity, with 5 arrays for both side and rear walls of the discharge chamber. The cusp field lines terminate on the anode surface. This magnetic circuit has been shown to enhance discharge confinement and ionization efficiency, thus reducing the ionization losses in the thruster. More detailed studies are required to determine if the discharge chamber can be radiation cooled, as is assumed here, or if active cooling may be required.

Ion Extraction Subsystem: To first order, the ion optics, that is, the screen and accelerator grids, drive the design of the entire engine in terms of power handling capability, thrust levels, specific impulse, thrust efficiency, and engine size. For megawatt level thrusters, there exists a considerable database on pulsed megawatt-level ion accelerators (magnetic bucket ion sources) which have been developed for neutral injection heating of fusion plasmas $39-42$ Although these ion extraction systems are capable of pulsed and steady-state (up to 30 seconds) operation at beam power and thrust densities of more than $65 \mathrm{MW} / \mathrm{m}^{2}$ and $45 \mathrm{~N} / \mathrm{m}^{2}$ respectively, they do so using light ions (hydrogen and deuterium) at high beam voltages $(>80 \mathrm{kV})$. The effective value of specific impulse for these systems is then on the order of 200,000 seconds, at a thrust to power ratio 47 times lower than existing xenon ion thruster accelerator technology. Because of the superior performance (high perveance, or current densities) of the close spaced ion thruster accelerator systems with heavy ions at the specific impulse values of interest, these form the basis for the megawatt design.

Current xenon ion thruster accelerator technology has demonstrated beam power and thrust densities of $0.27 \mathrm{MW} / \mathrm{m}^{2}$ and $9.2 \mathrm{~N} / \mathrm{m}^{2}$ respectively. ${ }^{38}$ This is equivalent to an argon thruster power density of $0.49 \mathrm{MW} / \mathrm{m}^{2}$. Beam current densities of more than 140 $\mathrm{A} / \mathrm{m}^{2}$ with xenon were achieved. If an argon current density of $153 \mathrm{~A} / \mathrm{m}^{2}$ at a total accelerating voltage of 2 $\mathrm{kV}$ is projected from low power systems characteristics, the maximum beam power and thrust as a function of specific impulse can be projected as functions of beam area (Figures 4 and 5).

The detailed point design of the ion extraction system consists of $100.5 \mathrm{~m} \mathrm{X} 1 \mathrm{~m}$ grid sections. Each section is made up of 2 molybdenum grids, $0.5 \mathrm{~mm}$ thick. These grids are cylindrically rolled with a $4 \mathrm{~cm}$ dish depth and a nominal $0.6 \mathrm{~mm}$ grid gap. The grids in each section have $\sim 1.2 \times 10^{5}$ aligned holes: screen grid holes are $1.9 \mathrm{~mm}$ diameter, accelerator holes are 1.1 $\mathrm{mm}$ diameter. The grids are supported by molybdenum and graphite structural elements. Each section is capable of operating independently. of the others; shorting of one section does not result in shutdown of the entire thruster. The dished grids, aligned holes and varying hole diameters insure proper focussing of the argon ion beam.

The maximum obtainable beam power density consistent with the above ion optics assumptions is approximately $0.25 \mathrm{MW} / \mathrm{m}^{2}$. The selected design and operating conditions of the megawatt-class point design are a $5 \mathrm{~m}^{2}$ beam area, a beam current of $690 \mathrm{~A}$ and a beam voltage of $1.68 \mathrm{kV}$, equivalent to an R-ratio of .84. Input power is then $1.27 \mathrm{MWe}$. The associated beam current and power densities are $138 \mathrm{~A} / \mathrm{m}^{2}$ and 0.23 $\mathrm{MW} / \mathrm{m}^{2}$. At these conditions, a thrust level of $25 \mathrm{~N}$ at $7800 \mathrm{~s}$ specific impulse is obtained. 
Beam Neutralization Subsystem: The neutralizer subsystem consists of 2 hollow cathodes, operating in a current-sharing mode and similar in design to the discharge cathodes, each designed for operation at a nominal $380 \mathrm{~A}$ emission current. To reduce the mass loss of ions and neutral species from the neutralizer system, these cathodes would incorporate an enclosed keeper geometry which should reduce the propellant mass flow rate requirement to a value equal to approximately 3 percent of the beam current.

Overall Ion Thruster Parameters: The above designs yield an estimated argon ion thruster system mass of $560 \mathrm{~kg}$. This mass accounts for the discharge cathodes, magnetic circuit, anode, thruster structure, ion extraction and acceleration grids and mounting structure, and neutralizer cathodes. At the operating point used for this study of $7800 \mathrm{~s}$ specific impulse, $1.25 \mathrm{MWe}$ input power per thruster, the resulting thruster system specific mass is $0.44 \mathrm{~kg} / \mathrm{kWe}$. With an additional $10 \%$ contingency as assumed in the MPD thruster estimate, thruster specific mass is $0.49 \mathrm{~kg} / \mathrm{kWe}$.

Ion thruster scaling is limited by the allowable current densities and electrode erosion rates at lower specific impulse. The lower limit in argon specific impulse for $2000 \mathrm{~V}$ total accelerating voltage is $6500 \mathrm{~s}$, based on a limiting R-ratio of 0.55 , and the upper limit is $8000 \mathrm{~s}$. A $3000 \mathrm{~V}$ accelerating voltage changes the applicable argon specific impulse range to $7000-9000$ s. For constant beam area, lower specific impulse would necessitate grid and discharge cathode redesign to accommodate higher current densities. Thruster power density would also decrease with decreasing specific impulse. The thruster design considered here is thus illustrative of one of the possible solutions to megawattclass ion engine design. The design and operating characteristics represent accurate first-order engineering estimates. This design does in most probability represent a fundamental limit in maximum beam powerto-beam area ratio for specific impulse values of interest to Lunar or Mars missions. Furthermore, performance estimates of specific impulse, thrust, and efficiency are accurate, as the physical principles of ion engine behavior have been observed extensively in low power devices.

\section{Power Management and Distribution (PMAD)}

Power conditioning and transmission line weights have been approximated based on rule-of-thumb estimates from experts at NASA Lewis Research Center in combination with projected performance of specific components and related system designs. ${ }^{43,44,45}$ The assumed power conditioning requirements were DC transmission over the reactor-to-payload separation distance of $100 \mathrm{~m}$, low voltage conversion for MPD thruster and magnet operation and for ion engine discharge and neutralizer power supplies, and high voltage power for ion engine screen and accelerator supplies. In the ion thruster, the grid power supply requires the majority of the input power. Suggested configuration utilized a $20-50 \mathrm{kHz}$ resonant invertor to convert the 3-phase AC output of a dynamic nuclear power conversion to $5000 \mathrm{~V} \mathrm{DC}$ for transmission to the thrusters. This voltage would then be converted to the appropriate voltage requirements for each thruster type. Inherent in each design would be allowances for switching, restart and high voltage fault clearing in the ion thruster systems. At this time, a detailed circuit diagram of a high reliability system has not been derived for megawatt levels.

System performance and mass estimates are based on projections from ongoing technology development efforts in NASA and the Strategic Defense Initiative Office. Radiator masses were estimated separately based on the PMAD efficiencies and are not included in the component specific masses. Projections for individual megawatt-class DC-DC converter units are currently $0.1 \mathrm{~kg} / \mathrm{kWe}$, at $95 \%$ efficiency and operating at $-600 \mathrm{~K} .43$ High current switches are anticipated to also be $0.1 \mathrm{~kg} / \mathrm{kWe}, 90 \%$ efficient at 600 . K. Overall system efficiency is estimated to be $95 \% 43$. Heat rejection at $600 \mathrm{~K}$ is estimated based on $\mathrm{a} \mathrm{kg} / \mathrm{m}^{2}$ carbon-carbon composite pumped loop radiator design for Stirling engine applications ${ }^{46}$. Power conditioning radiator mass is calculated to be on the order of 0.1 $\mathrm{kg} / \mathrm{kWe}$, where the reference power is the full rated power of the entire propulsion system, $10 \mathrm{MWe}$. Total power conditioning specific mass, including structure and heat rejection, is estimated to be $2 \mathrm{~kg} / \mathrm{kWe}$.

Transmission line requirements are also based on the assumed $5000 \mathrm{~V} \mathrm{DC}, 100 \mathrm{~m}$ transmission assumption stated above. Because the vehicle is assumed to operate in the Low Earth Orbit environment, in the presence of an ambient plasma, the high voltage line is assumed to be coaxial and shielded from the external environment. Transmission cable masses were scaled from studies of SP-100 power supplies tethered to the Space Station. 44,45 These systems assumed polymer filled coaxial tubing with debris shielding for a seven year life in LEO, which is more than adequate for an interplanetary vehicle. A redundancy of $100 \%$ was included in these designs. A total mass of $0.5 \mathrm{~kg} / \mathrm{kWe}$ was estimated for the distances and power levels required for multimegawatt 
electric propulsion. Some reduction in mass may result from the use of more advanced gas insulated coaxial lines, rather than polymer insulation; however, the polymer insulation allows greater flexibility in deployment and storage of the cabling. The total PMAD mass of $2.5 \mathrm{~kg} / \mathrm{kWe}$ was found to be in close agreement with previous assessments of Nuclear Electric Propulsion systems for a piloted Mars Mission. ${ }^{47}$

\section{Additional Propulsion System Design Impacts}

The MPD and ion thruster systems will require subsystems common to both concepts, such as propellant distribution, gimballing, and mounting structure. Propellant flow rates of $1-3 \mathrm{~g} / \mathrm{s}$ are projected for both thruster systems. Propellant distribution system masses are anticipated to be a small portion of the overall system mass, depending on the location of the propellant tanks with respect to the propulsion system on a given vehicle design. Gimbals and mounting have previously been estimated to mass approximately $30 \%$ of the thruster mass ${ }^{48}$; however, detailed assessment of engine pointing requirements will strongly depend on the location of the propulsion system relative to the vehicles' center of mass. In addition, the steering of 2 to $40 \mathrm{~m}^{2}$ of thrusters massing thousands of kilograms may result in steering strategies very different from current. vehicle design estimates.

\section{Thruster Research and Development Requirements}

In the case of either MPD or ion thrusters, a primary development requirement is testing facilities capable of operating for long time periods at power levels of $1-10 \mathrm{MWe}$ at pressures on the order of $10^{-4}$ to $10^{-5}$ torr. Currently, facilities at NASA Lewis Research Center are anticipated to operate MPD thrusters at power levels up to $1 \mathrm{MWe}$ for times on the order of an hour. The use of larger cryogenic panels may increase this capability to the multimegawatt level for comparable periods. However, the long thrusting periods required for low acceleration missions impose the need for significantly longer testing periods to determine thruster lifetime limits. A major investment in vacuum facilities will be required to fulfill these requirements. Diagnostic techniques suitable for measuring thruster electrode erosion may be required to enable lifetime prediction, as well as thruster health monitoring for mission applications. Further development and testing of space ready power conditioning subsystems for either thruster type is also required, including testing these systems in a vacuum environment.

Engines similar to the designs described herein have yet to be operated. For the MPD thruster, the chief research issues are demonstration of the cathode lifetimes and performance (specific impulse, efficiency) projected above. Cathode endurance is dependent on the behavior of both conventional thoriated tungsten and impregnated tungsten cathodes operating under MPD thruster conditions, although suitable lifetimes have in fact been shown for current densities comparable to the MPD thruster design constraints ${ }^{29}$. Thruster efficiencies and specific impulse limits require further experiments and modelling to determine the dominant loss mechanisms in the discharge. The full integrated system design - thruster, magnet, and radiator - could be demonstrated simultaneously with some development of the necessary lithium heat pipe technology, and the use of cryogenic hydrogen in the laboratory model.

Megawatt class ion engines require development of the capability to manufacture large span grids with close tolerances with the ability to tolerate electrostatic and thermal stresses without excessive deformation. High current density cathodes with lifetimes of 10,000 hours must also be developed and tested. Life testing of low power ion engines has been demonstrated satisfactorily; similar tests of megawatt level engines will put demands on grid materials and design. Reliable thermal management of the discharge chamber assembly must also be achieved.

\section{Exploration Mission Requirements and Performance}

Exploring the Moon and Mars imposes stringent demands upon any space propulsion system. Specific demands are dependent upon mission scenarios; however, some requirements are common to all missions. The initial mission requirements assumed in designing the megawatt level electric propulsion systems resulted from earlier preliminary mission analyses of manned and cargo electric vehicles. As is the case with all low-acceleration, power- limited propulsion systems, mission performance depends upon payload mass, propulsion system mass/power ratio (specific mass), power level, specific impulse, and thrust efficiency. Initial parameters for thruster design were generated from typical values derived from past and ongoing studies. Two reference missions were selected for characterizing electric propulsion system requirements: A Mars cargo mission and a Mars piloted mission. Ground rules/assumptions for the cargo mission werel

$5 \mathrm{MWe}$ NEP and SEP systems, 16 and 12 $\mathrm{kg} / \mathrm{kWe}$ respectively

2020 time frame 
$400 \mathrm{MT}$ payload

Depart from Low Earth Orbit (LEO) of $407.5 \mathrm{~km}$

Arrive at Mars areosynchronous Orbit of 6000 km

Option to return to geosynchronous Earth orbit (GEO) of $35800 \mathrm{~km}$

$5000 \mathrm{~s}$ specific impulse, 0.675 thrust efficiency representative of both argon ion and MPD thruster projected performance capabilities.

Ground rules/assumptions for the piloted mission were?

$10 \mathrm{MWe}$ NEP and SEP systems, $10 \mathrm{~kg} / \mathrm{kWe}$

2015 time frame

$124 \mathrm{mt}$ payload to Mars, $40.3 \mathrm{mt}$ returned to Earth

$7000 \mathrm{~s}$ specific impulse, thrust efficiency based on argon ion performance projections.

Depart from and return to LEO; crew boards spacecraft beyond Van Allen radiation belts

Arrive at Mars Deimos orbit of 20077 km; crew disembarks during spiral in to Mars, rejoins vehicle during spiral escape from Mars.

Crew disembarks for return to LEO from beyond Van Allen radiation belts; NEP vehicle continues to spiral in to LEO.

A review of the one-way cargo mission studies results is given in Figure 7.

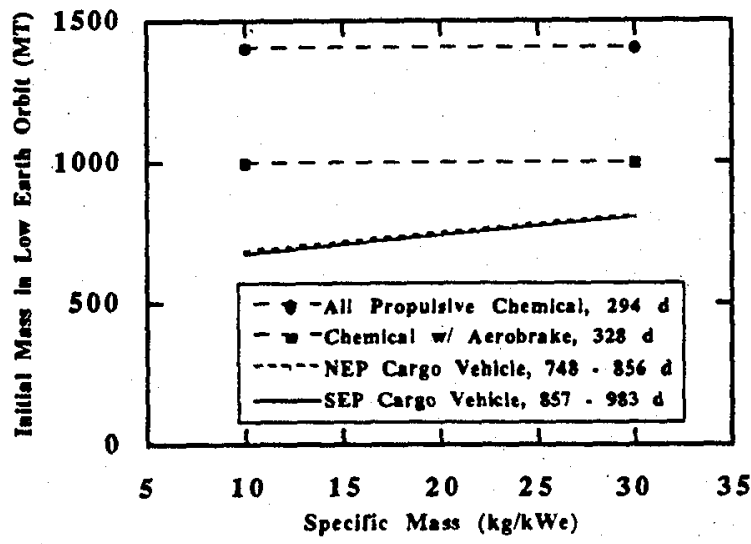

Figure 7. Comparison of NEP and SEP Mars Cargo Vehicles with Chemical Propulsion, 2010 Opportunity.

In both studies, propulsion system specific masses included power supply, heat rejection, power conditioning, and thrusters, based on nuclear and solar photovoltaic system designs and preliminary projections of thruster masses. The selected nuclear power systems used Brayton or Rankine dynamic cycles in conjunction with SP-100 reactor technologies. The SEP vehicle study investigated several forms of photovoltaic cells, focussing primarily on Indium Phosphide and Multijunction cell technologies as the most promising. The dynamic systems produced power in an AC mode, requiring $A C-D C$ power conditioning; the solar cells operate in a DC mode, requiring only voltage regulation and transmission.

In cases where thruster operating time extended significantly beyond their projected lifetime, spare thrusters were included in the cargo vehicle mass estimates. Because of the large payload assumed in the cargo vehicle study, thruster operating demands were greatest for this case. Operating times of 20,000 to 30,000 hours were required for the one-way trip for the cargo vehicle. In the case of the piloted mission, with lower payload and a higher power level, thrusting times of $10,000-20,000$ hours were required, indicating the need for additional thrusters based on lifetime goals identified in both the argon ion and MPD thruster designs. The corresponding total impulse requirement is $\sim 7.8 \times 10^{9}-1.4 \times 10^{10} \mathrm{~N}$-s. The thrusting time, total impulse, and power level were the primary inputs into the more detailed thruster designs describe above.

Final thruster point designs have been assessed for their mission performance in the reference NEP piloted mission as stated above. The results of this preliminary study are shown in Figure 8. Each curve represents a series of trajectory optimization calculations, in which launch date, outbound and inbound leg times, and vehicle steering were varied to determine the minimum initial mass combination for a given total trip time. For the ion thruster, an specific impulse of $7800 \mathrm{~s}$ and a specific mass of $.49 \mathrm{~kg} / \mathrm{kWe}$ were assumed; for the MPD thruster, an specific impulse of $6000 \mathrm{~s}$ and a specific mass of $.17 \mathrm{~kg} / \mathrm{kWe}$ were assumed. PMAD masses were assumed to be 2.5 $\mathrm{kg} / \mathrm{kWe}$, including power conditioning and transmission lines. To assess a range of specific masses in a parametric fashion, total propulsion system specific masses of 7 and $10 \mathrm{~kg} / \mathrm{kWe}$ were assessed for a constant power level of $10 \mathrm{MWe}$. The range of specific masses may be considered to represent a comparison between $10 \mathrm{MWe}$ nuclear power systems with redundant thrusters at $10 \mathrm{~kg} / \mathrm{kWe}$ and $7 \mathrm{~kg} / \mathrm{kWe}$, representing the current estimated range of space nuclear power technologies.

All four systems show low masses and comparable trip times less than 600 days. The benefits 
of the ion engine's higher specific impulse and efficiency are evident in the slight improvement in mission performance over the MPD thruster, although some of this difference may be erased should the MPD thruster prove to be capable of comparable specific impulse. It should be noted that thruster specific masses are a small portion of the whole system mass in these cases. Should very lightweight power supply/PMAD options become available in the specific mass range below 5 $\mathrm{kg} / \mathrm{kWe}$, electric propulsion systems in the tens to hundreds of megawatts may become desirable. In that case, both thruster specific mass and power handling capability will play a more dominant role in system performance.

The present mission results are not capable of determining the correct thruster choice at this time, as both concepts require development to the MWe level, and additional mission constraints such as launch vehicle sizing or operations may ultimately be the discriminating factor.

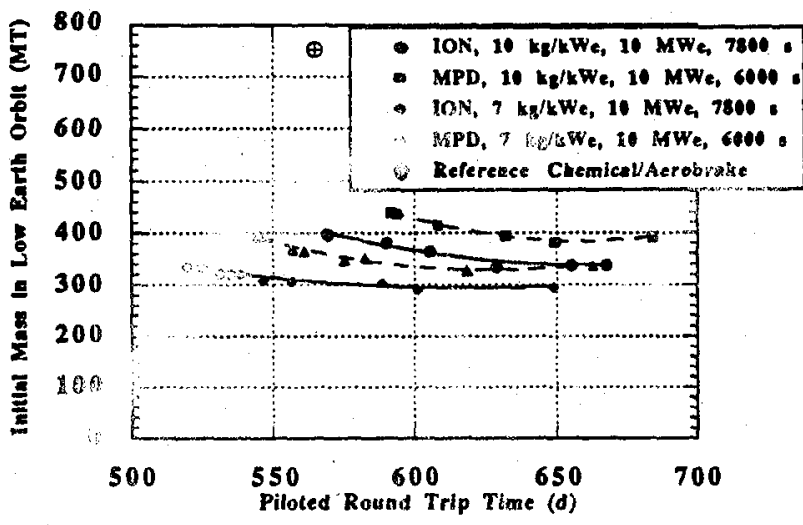

Figure 8. MPD and Ion Thruster Performance Comparison, Piloted Mars Mission, 2016 Opportunity

\section{Conclusions}

An MPD thruster system using hydrogen propellant has been projected to process high power levels $(1-3$ $\mathrm{MWe}$ ) in a small volume at specific impuises of around $6000-7000$ seconds and efficiencies on the order of $60 \%$. The small size of these devices allows them to operate at specific masses of $.17 \mathrm{~kg} / \mathrm{kWe}$, with thrusters sized at $\sim 1 \mathrm{~m}$ diameter, including a passive anode heat rejection system. Experimental data indicate that an applied field may increase thruster performance and a regeneratively cooled field coil has been included in the design. Thruster lifetimes of at least 10,000 hours are estimated based on research using thoriated tungsten and impregnated tungsten cathodes.

A 1.25 MWe argon ion thruster point design projected to process $1.25 \mathrm{MWe}$ at $7800 \mathrm{~s}$ specific impulse and 76\% thrust efficiency has been developed to illustrate the capabilities and sizing constraints of these systems. Thruster sizing was based on the experimentally demonstrated power and current densities of low power systems, in order to maintain lifetime projections of 10,000 hours. A ring-cusp magnetic circuit was used in concert with "race track" hollow cathode discharge system to allow an efficient, large scale discharge chamber. Scaling of the thruster power handling capability with discharge area and specific impulse has been estimated, based on the point design system. A specific mass of $.49 \mathrm{~kg} / \mathrm{kWe}$ was obtained for the $1 \mathrm{~m} \mathrm{X} 5 \mathrm{~m}$ point design system.

Both Magnetoplasmadynamic and ion thrusters have been assessed for application to Mars missions of interest to the Space Exploration Initiative (SEI). The mission requirements of these systems have been assessed through preliminary mission studies based on piloted and cargo missions using solar and nuclear electric power. For this preliminary mission study, power levels of $5-10 \mathrm{MWe}$ were assumed for the cargo and piloted missions, respectively. A significant reduction in system initial mass over reference chemical/aerobrake vehicles can be derived using either electric propulsion system. The particular mission assumptions of power level, specific impulse, efficiency, and thruster lifetimes have been incorporated into preliminary designs of both thruster concepts. A preliminary mission analysis of both point designs for the reference piloted NEP Mars mission show mass reduction benefits using either system. Further mission benefits must be assessed using a fully integrated power/PMAD/propulsion system to determine the actual benefits with operational aspects such as redundancy accounted for. Development requirements for both MPD and ion thrusters have been described. Prime requirements are MWe level testing facilities for either device, as well as a life test methodology for these inherently extended operation systems.

\section{Acknowledgements}

The authors would like to thank Dr. Ira Myers for several productive conversations on power conditioning systems for electric propulsion designs.

\section{REFERENCES}

1.) Mason, L. S., Hack, K. J., and Gilland, J. H. "Nuclear Electric Propulsion for Mars Cargo Missions," 
in Transactions of the Seventh Symposium on Space Nuclear Power Systems, January 7-10, 1990.

2.) NASA, "Report of the 90-Day Study on Human Exploration of the Moon and Mars," November, 1989.

3.) Palaszewski, B. "Electric Propulsion for Manned Mars Exploration," presented at the JANNAF Propulsion Meeting, 1989.

4.) Stuhlinger, E. Ion Propulsion for Space Missions, McGraw-Hill Publishing Co., New York, 1964.

5.) Stuhlinger, E., and King, J. C. "Concept for a Manned Mars Expedition with Electrically Propelled Vehicles," in Electric Propulsion Development, Progress in Astronautics and Aeronautics vol. 9, Ernst Stuhlinger, ed., 1963, pp. 647-664.

6.) English, R., et. al., "A 20,000-Kilowatt Nuclear Turboelectric Power Supply for Manned Space Vehicles," NASA Memorandum MEMO 2-20-59E, 1959.

7.) Coomes, E. P. et. al., "PEGASUS: A MultiMegawatt Nuclear Electric Propulsion System," AIAA Paper No. 86-1583, 1986.

8.) Cassady, R. J. "An MPD Thruster Driven Cargo Ferry for Support of the Manned Mars Mission," AIAA Paper No. 88-2896, 1988.

9.) Sercel, J. and Krauthamer, S. "Multimegawatt Nuclear Electric Propulsion; First Order System Design and Performance Evaluation," AIAA Paper No. 86-1202, 1986.

10.) Galecki, D. L., and Patterson, M. J. "Nuclear Powered Mars Cargo Transport Mission Utilizing Advanced Ion Propulsion," AIAA Paper No. 87-1903, 1987.

11.) Loeb, H. W. "Electric Propulsion for Manned Spaceflights of the Future," AIAA Paper No. 87-0707, 1981.

12.) Beattie, J.R., et. al. "Xenon Ion Propulsion Subsystem," AIAA Paper 85-2012, 1985

13.) Patterson, M.J. "Performance Characteristics of Ring-Cusp Thrusters with Xenon Propellant," AIAA Paper No. 86-1392, 1986.

14.) Rawlin, V. K., and Patterson, M.J. "High Power
Ion Thruster Performance," in Transactions of the Fourth Symposium on Space Nuclear Power Systems, January 12-16, 1987.

15.) Nakanishi, S. and Pawlik, E. "Experimental Investigation of a 1.5-m-diam Kaufman Thruster," $\mathbf{L}$ Spacecraft, Vol. 5, No. 7, July 1968. pp. 801-807.

16.) Polk, J.F., Kelly, A.J., and R.G. Jahn "MPD Thruster Erosion Research," AIAA Paper No. 87-0999, 1987.

17.) Yoshikawa, T., et. al. "Continuous Operation of a Quasi-Steady MPD Propulsion System with an External Magnetic Field," IEPC Paper No. 88-056, 1988.

18.) Tahara, H. and Yoshikawa, T. "Hybrid MPD Thruster with Axial and Cusp Magnetic Fields," IEPC Paper No. 88-058, 1988.

19.) Kurtz, H. L. et. al. "Cylindrical Steady-State MPD Thruster," IEPC Paper No. 88-025, 1988.

20.) Merke, et. al. "Nozzle Type MPD Thruster Experimental Investigations," IEPC Paper No. 88-028, 1988.

21.) Gilland, J. H., Kelly, A. J., and Jahn, R. G. "Scaling of MPD Thrusters," AIAA Paper No. 87. 0997, 1987.

22.) Dunn, P.D. and Reay,D. A. Heat Pipes, 3rd ed., Pergamon Press, 1982.

23.) Choueiri, E. Y., Kelly, A. J., and Jahn, R. G. "MPD Thruster Plasma Instability Studies," AIAA Paper No. 87-1067, 1987.

24.) Tahara, H., et. al. "Development of a QuasiSteady MPD Arcjet Thruster for Near Earth Missions," AIAA Paper No. 87-1001, 1987.

25.) Mantenieks, et. al. "Performance of an $100 \mathrm{~kW}$ Class Applied Field MPD Thruster," AIAA Paper No. 89-2710, 1989.

26.) Myers, R. M., Mantenieks, M., and Sovey, J.S. "Geometric Effects in Applied Field MPD Thrusters," AIAA Paper No. 90-2669, to be presented at 21st International Electric Propulsion Conference, Orlando, FL, July 18-20, 1990.

27.) Sasoh, A., Solem, A. and Arakawa, Y. 
"Optimization of Current Distribution in an AppliedField MPD Thruster," IEPC Paper No. 88-057, 1988.

28.) Myers, R.M., Kelly, A.J., and Jahn, R.G. "Energy Deposition in Low Power Coaxial Plasma Thrusters," IEPC Paper No. 88-024, 1988.

29.) Shroff, A., et. al. "Life Tests of Impregnated Cathodes," Appl.Surf. Sci, Vol. 8, 1981, pp 36-49.

30.) Myers, R. M., Suzuki, N., Kelly, A.J. and Jahn, R.G. "Cathode Phenomena in a Low-Power MPD Thruster," AIAA Paper No. 88-3206, 1988.

31.) Jahn, R. G. Physics of Electric Propulsion. McGraw Hill, NY, NY, 1968.

32.) Burton, R. L., Clark, K. E., and Jahn, R.G. "Measured Performance of a Multimegawatt MPD Thruster," L. Spacecraft, Vol. 20, No. 3, May-June 1983, pp. 299-304.

33.) Wolff, M., Kelly, A.J., and Jahn, R.G. "A High Performance Magnetoplasmadynamic Thruster," IEPC Paper No. 84-32, 1984.

34.) King, D.Q., Smith,W.W., Jahn, R.G., and Clark, K.E. "Effect of Thrust Chamber Configuration on MPD Arcjet Performance:" MIAA Paper No. 79-2051, 1979.

35.) Connolly, D.J., Bishop, A.R., and Seikel, G.R., "Tests of Permanent Magnet and Superconducting MPD Thrusters," AIAA Paper No. 71-696, 1971.

36.) Brechna, H. Superconducting Magnet Systems, Springer Verlag, 1973.

37.) Wilbur, P.J., Beattie, J.R., and Hyman, J. "An Approach to the Parametric Design of Ion Thrusters," IEPC Paper No. 88-080, 1988.

38.)Patterson, M.J., and Rawlin, V.K. "Performance of 10-kWe Class Xenon Ion Thrusters," AIAA Paper 882914, 1988.

39.) Menon, M.M., et. al. "Quasi-steady-state Multimegawatt Ion Source for Neutral Beam Injection," Rev. Sci. Instrum., 56(2), Feb. 1985, pp. 242-249.

40.) Tsai, C.C., et. al. "Long-pulse Ion Source for Neutral-Beam Applications," Rev, Sci.Instrum., 53(4), April 1982, pp. 417-423.

41.) Gardner, W.L., et al. "Properties of an Intense 50-
kV Neutral-Beam Injection System," Rev. Sci. Instrum, 53(4), April 1982, pp. 424-431.

42.) Weber, P.D., et. al. " $120-\mathrm{kV}$ Testing of a $10 \times 40$ $\mathrm{cm}$ prototype of the US. Common Long Pulse Neutral Beam Source," Rev. Sci.Instrum, 57(11), November 1986, pp. 2714-2719.

43.) Myers, Ira. Personal Communication. April, 1990.

44.) Bents, D. J. "Power Transmission Studies for Tethered SP-100," Proceedings of the 23rd Intersociety Energy Conversion Engineering Conference, Denver, CO, July 31 - August 5, 1988, pp. 733-741.

45.) Switzer, C. and Bents, D. "Coaxial Tube Array Space Transmission Line Characterization, "Proceedings of the 22nd Intersociety Energy Conversion Engineering Conference, Philadelphia, PA, August 10-14, 1987, pp. 565-570.

46.) Beggs, L. and Engdahl, E. "Advanced Radiator Concepts," "Proceedings of the 24th Intersociety Energy Conversion Engineerring Conference, Washington D.C., August 6-11, 1989, pp. 75-80.

47.) Bents, D., et al. "Power System Technologies for the Manned Mars Mission," in Manned Mars Working Group Papers, 1987.

48.) Byers, D., Terdan, F., and Myers, I., "Primary Electric Propulsion for Future Space Missions, " NASA TM 79141, 1979. 



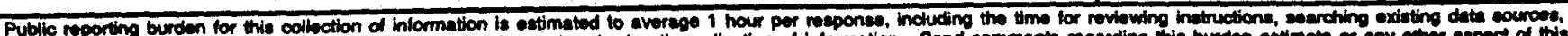

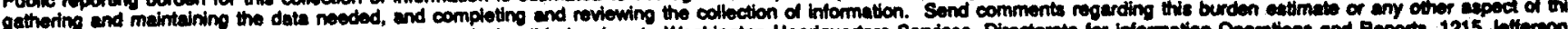

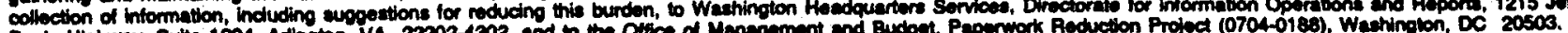

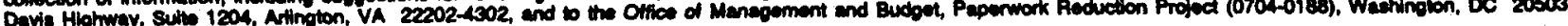

\begin{tabular}{|l|c|c|}
\hline 1. AGENCY USE ONLY (Leave blank) & $\begin{array}{c}\text { 2. REPORT DATE } \\
\text { August } 1991\end{array}$ & $\begin{array}{r}\text { 3. REPOAT TYPE AND DATES COVEAED } \\
\text { Technical Memorandum }\end{array}$
\end{tabular}

\section{TIME AND BUBTITLE}

Multimegawatt Electric Propulsion System Design Considerations

5. FUNDINO NUMBERS

AUTHOA(S)

J.H. Gilland, R.M. Myers, and M.J. Patterson

TA -YSZ9710

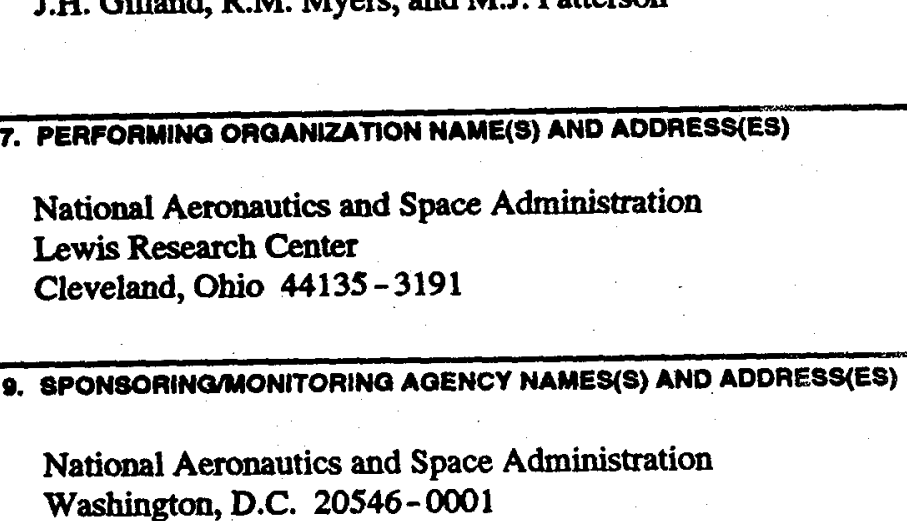

Washington, D.C. 20546-0001

8. performino organization REPORT NUMBER

E-6437

11. SUPPLEMENTARY NOTES

Prepared for the 21st International Electric Propulsion Conference sponsored by the American Institute of Aeronautics and Astronautics, Orlando, Florida, July 18-20, 1990. J.H. Gilland and R.M. Myers, Sverdrup Technology, Inc., Lewis Research Center Group, 2001 Aerospace Parkway, Brook Park, Ohio 44142; MJ. Patterson, NASA Lewis Research Center. Responsible person, J.H. Gilland, (216) 977-7093.

12. DISTAIBUTIONAVAILABILITY STATEMENT 12b. DISTRIBUTION CODE

Unclassified - Unlimited

Subject Category 20

\section{ABstaACT (Maximum 200 worda)}

Piloted Mars mission requirements of relatively short trip times and low initial mass in Earth orbit as identified by the NASA Space Exploration Initiative, indicate the need for multimegawatt electric propulsion systems. The design considerations and results for two thruster types, the argon ion and hydrogen magnetoplasmadynamic thrusters, are addressed in terms of configuration, performance, and mass projections. Preliminary estimates of Power Management and Distribution for these systems are given. Some assessment of these systems' performance in a reference Space Exploration Initiative piloted mission are discussed. Research and development requirements of these systems are also described.

\section{SUBNECT TERMS}

Electric propulsion; MPD thruster; Ion thruster

\begin{tabular}{|c|c|}
\hline 17. SECURITY CLASSIFICATION & $\begin{array}{c}\text { 18. SECURITY CLASSIFICATION } \\
\text { OF REPORT } \\
\text { Onclassified }\end{array}$ \\
Unclassified
\end{tabular}
19. SECURITY CLASSIFICATION OF ABSTRACT Unclassified 
National Aeronautics and

Space Administration

Lewis Research Center

Cleveland, Ohio 44135

Official Business

Penalty for Private Use $\$ 300$
FOURTH CLASS MAIL

ADDRESS CORRECTION REQUESTED

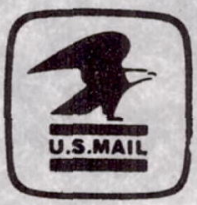

Postage and Fees Paid Natıonal Aeronautıcs and Space Administration NASA 451 